\title{
Haemonchus contortus: spatial risk distribution for infection in sheep in Europe
}

Laura Rinaldi ${ }^{1}$, Dolores Catelan ${ }^{2}$, Vincenzo Musella ${ }^{3}$, Lorenzo Cecconi ${ }^{2}$, Hubertus Hertzberg 4 , Paul R. Torgerson ${ }^{5}$, Fabien Mavrot ${ }^{5}$, Theo de $\mathrm{Waal}^{6}$, Nikolaos Selemetas ${ }^{6}$, Tom Coll $^{7}$, Antonio Bosco ${ }^{1}$, Annibale Biggeri ${ }^{2}$, Giuseppe Cringoli ${ }^{1}$

${ }^{1}$ Department of Veterinary Medicine and Animal Productions, University of Naples Federico II, Naples, Italy, CREMOPAR Campania Region, Naples, Italy; ${ }^{2}$ Department of Statistics, Informatics and Applications "G. Parenti", University of Florence, Florence, Italy; ${ }^{3}$ Department of Health Sciences, University "Magna Grocia" of Catanzaro, Catanzaro, Italy; ${ }^{4}$ Institute of Parasitology, Vetsuisse Faculty, University of Zurich, Zurich, Switzerland; ${ }^{5}$ Section of Epidemiology, Vetsuisse Faculty, University of Zurich, Zurich, Switzerland; ${ }^{6} U C D$ School of Veterinary Medicine, University College Dublin, Dublin, Ireland; ${ }^{7}$ Teagasc, Mohill, Co Leitrim, Ireland

\begin{abstract}
Haemonchus contortus is a species of gastrointestinal strongyles of primary concern for sheep. This highly pathogenic, blood-feeding helminth negatively influences animal health, welfare and productivity. In order to elucidate the current scenario in terms of prevalence and intensity of $H$. contortus infection in sheep farms across Europe, a standardized crosssectional survey was conducted in three pilot areas in Ireland, Switzerland and Italy, all part of the EU funded GLOWORM project. Two consecutive field surveys (in 2012 and 2013) were conducted in the three countries in the same period (AugustOctober) in 259 sheep farms in total. Harmonized, diagnostic procedures (from farm to laboratory) based on pooled samples, the FLOTAC technique and coproculture were used. The georeferenced parasitological results were modelled (at the pilot area level) following a Bayesian geostatistical approach with correction for preferential sampling and accounting for climatic and environmental covariates. The observed H. contortus prevalence rates did vary between the countries showing high values in Switzerland $(77 \%)$ and Italy (73\%) compared to Ireland (4\%). Spatial patterns of H. contortus distribution were detected in Switzerland and Italy with a north-south gradient. The latent factor analysis highlighted the importance of seasonality and annual cyclicity within country (particularly in southern Italy), while mean temperature and rainfall dominated between country variations in the prevalence of $H$. contortus infection.
\end{abstract}

Keywords: Haemonchus contortus, gastrointestinal strongyles, spatial statistics, geographical information systems, sheep, Europe.

\section{Introduction}

Among parasitic infections of ruminants, gastrointestinal (GI) strongyles - caused by different genera of helminths (e.g. Haemonchus, Ostertagia, Teladorsagia, Trichostrongylus, Cooperia, Oesophagostomum, Chabertia) - continue to cause significant economic and welfare burden to the global livestock industry in Europe (Morgan et al., 2013; Charlier et al., 2014; Rinaldi and Cringoli, 2014). The ranking of these GI parasitic worms as one of the top causes of lost produc-

\footnotetext{
Corresponding author:

Laura Rinaldi

Unit of Parasitology and Parasitic Diseases

Department of Veterinary Medicine and Animal Productions

University of Naples Federico II

Via della Veterinaria 1, 80137 Naples, Italy

$\mathrm{Tel} / \mathrm{Fax}+39081253-6283$

E-mail: lrinaldi@unina.it
}

tivity in ruminants (http://www.discontools.eu) reinforces the increasing consideration in the European Union (EU) of the impact of strongyles upon animal health and productivity. However, these infections in grazing ruminants are often neglected with research and implementation of modern surveillance methods in this area remaining behind, mainly with regard to standardized diagnostic methods, surveillance and sustainable control strategies (Rinaldi and Cringoli, 2014).

Haemonchus contortus is a GI strongyle species of primary concern for small ruminants. It is a highly pathogenic, blood-feeding helminth that not only cause anaemia, but often also death in heavily infected animals (Burke et al., 2007). H. contortus has a very high propensity to develop resistance to anthelmintics (Kaplan et al., 2004) and drug resistance has been reported in farmed ruminants across Europe (reviewed in Rose et al., 2015). Geographically, it is widely distributed in tropical (between latitudes $23.5 \mathrm{~N}$ and 
23.5 S) as well as various subtropical climate zones (O'Connor et al., 2006). Prevailing climate (temperature, rainfall and moisture) and husbandry management practice are considered the main factors driving its spatial and temporal distribution.

Despite the parasite's strong association with tropical climates (Kao et al., 2000; O'Connor et al., 2006), its distribution range has recently expanded in northern temperate countries such as the UK where H. contortus in sheep is no longer rare (Kenyon et al., 2009; Burgess et al., 2012). Cases in Sweden (Hoglund et al., 2009) and Norway (Domke et al., 2013) have also been reported. Changes in climatic conditions have been implicated as the major driving force behind this expansion (van Dijk et al., 2008; Kenyon et al., 2009; Bolajoko et al., 2015). However, the spatial and temporal distribution of $H$. contortus is heterogeneous and depends on many different variables that vary from area to area, even from farm to farm (Musella et al., 2011). It is therefore important to monitor the prevalence and distribution of this helminth species to better plan sustainable control using targeted treatment and/or targeted selective treatment strategies (Cringoli et al., 2008; Kenyon et al., 2009).

In order to update the spatial distribution of risk of $H$. contortus infection in sheep farms across Europe, the aim of the present paper is to report the results of a standardized, cross-sectional survey conducted in the August-October period in 2012 and 2013 in three pilot areas of Ireland, Switzerland and Italy as part of the GLOWORM project, funded by the European Commission's (EC) seventh framework programme (FP7).

\section{Materials and methods}

The study area and sampling strategies have been described in a companion paper by Rinaldi et al. (2015). Briefly, two standardized coprological, crosssectional surveys were conducted in 2012 and 2013 (August to October) on sheep farms $(\mathrm{n}=361$ ) located in pilot areas of three key European countries: Ireland (Sligo and Leitrim Counties), Switzerland (the cantons Zürich, Aargau, Thurgau and St. Gallen) and Italy (the Campania region).

Once at the laboratory of each country, the faecal samples were vacuum-packed and couriered to the central laboratory in Italy, where they were analysed using a harmonized diagnostic procedure that involved pooling samples (Rinaldi et al., 2014) and use of the FLOTAC dual technique (Cringoli et al., 2010; Rinaldi et al., 2011), with an analytic sensitivity of 6 eggs per gram (EPG) of faeces. A sodium chloridebased flotation solution $(\mathrm{NaCl}$, specific gravity $=$ 1.200) was used to detect and count the GI strongyles eggs as described by Rinaldi et al. (2011) (Fig. 1a). The total number of pooled samples examined from the 361 sheep farms was 1,079 (327 pools from young and 752 from adult sheep).

In order to identify $H$. contortus among the different GI strongyles present in mixed infections, a composite faecal culture (MAFF, 1986) was conducted for each farm. However, the predefined culture numbers $(n=361)$ could not be met for all farms since the amount of faeces was not always sufficient. The total number of farms tested by both FLOTAC and the coproculture approach was 259 (72\% of the farms). $H$. contortus third-stage (L3) larvae were identified using the morphological keys proposed by van Wyk and Mayhew (2013) (Fig. 1b).

A geographical information system (GIS) was constructed utilizing the parasitological, climatic and environmental variables of the pilot areas in the three countries as data layers as reported by Rinaldi et al. (2015). The georeferenced parasitological data on H. contortus from the 259 sheep farms in the pilot areas from Ireland, Switzerland and Italy were used to construct a Bayesian geostatistical model with correction for preferential sampling and accounting for GIS and remotely sensed covariates (Catelan et al., 2015).

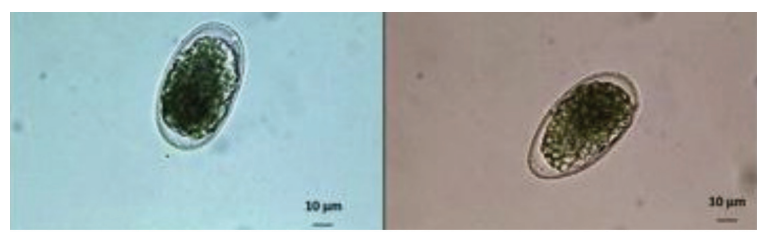

A

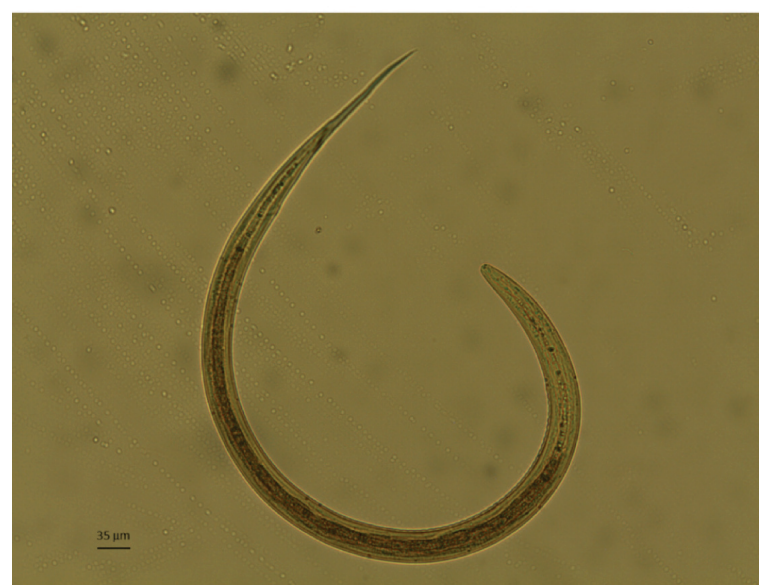

B

Fig. 1. Eggs of GI strongyles as they appear in the FLOTAC procedure (A) and third stage (L3) larva of H. contortus (B) (400X magnification). 
Table 1. Prevalence and eggs per gram (EPG) of gastrointestinal strongyles in sheep farms from the studied pilot regions within the GLOWORM project in 2012-2013.

\begin{tabular}{|c|c|c|c|c|c|c|c|c|c|}
\hline \multirow{3}{*}{ Country } & \multirow{2}{*}{\multicolumn{3}{|c|}{$\begin{array}{l}\text { Number of } \\
\text { sampled } \\
\text { sheep farms }\end{array}$}} & \multicolumn{6}{|c|}{ Gastrointestinal strongyles in sheep farms in pilot areas from three European countries } \\
\hline & & & & \multicolumn{3}{|c|}{$\begin{array}{l}\text { Number of positive farms (\%) } \\
(95 \% \text { Confidence Interval) }\end{array}$} & \multicolumn{3}{|c|}{$\begin{array}{c}\text { Mean EPG } \\
\left(25^{\text {th }}-50^{\text {th }}-75^{\text {th }} \text { percentiles }\right)\end{array}$} \\
\hline & 2012 & 2013 & Total & 2012 & 2013 & Total & 2012 & 2013 & Total \\
\hline Ireland & 32 & 41 & 73 & $\begin{array}{c}32(100.0 \%) \\
(89.1-100.0 \%)^{*}\end{array}$ & $\begin{array}{c}41(100.0 \%) \\
(91.4-100.0 \%)^{*}\end{array}$ & $\begin{array}{c}73(100.0 \%) \\
(95.1-100.0 \%)^{*}\end{array}$ & $\begin{array}{c}175.7 \\
(50.6-120.1-236.5)\end{array}$ & $\begin{array}{c}151.6 \\
(59.4-92.0-165.9)\end{array}$ & $\begin{array}{c}162.1 \\
(56.0-100.8-206.7)\end{array}$ \\
\hline Switzerland & 73 & 126 & 199 & $\begin{array}{l}69(94.5 \%) \\
(85.8-98.2 \%)\end{array}$ & $\begin{array}{l}113(89.7 \%) \\
(82.7-94.2 \%)\end{array}$ & $\begin{array}{l}182(91.5 \%) \\
(86.4-94.8 \%)\end{array}$ & $\begin{array}{c}606.7 \\
(138.0-279.0-645.0)\end{array}$ & $\begin{array}{c}586.8 \\
(70.5-249.0-624.0)\end{array}$ & $\begin{array}{c}594.2 \\
(95.2-261.5-640.5)\end{array}$ \\
\hline Italy & 28 & 61 & 89 & $\begin{array}{c}28(100.0 \%) \\
(87.7-100.0 \%) *\end{array}$ & $\begin{array}{c}57(93.4 \%) \\
(83.2-97.8 \%)\end{array}$ & $\begin{array}{c}85(95.5 \%) \\
(88.2-98.5 \%)\end{array}$ & $\begin{array}{c}461.8 \\
(117.0-243.0-573.0)\end{array}$ & $\begin{array}{c}562.3 \\
(115.0-335.0-820.0)\end{array}$ & $\begin{array}{c}529.2 \\
(119.5-321.0-790.0)\end{array}$ \\
\hline
\end{tabular}

$* 97.5 \%$ one-sided confidence interval.

\section{Results}

\section{Observed field data}

Table 1 reports, for each pilot area and for each study year, the number of farms positive for GI strongyles, the prevalence (number of positive farms over the total number of farms), $95 \%$ confidence intervals $(\mathrm{CI})$, and the intensity of GI strongyle infection (mean EPG calculated on positive pools, including the $25^{\text {th }}, 50^{\text {th }}$ and $75^{\text {th }}$ percentiles). The overall prevalence of GI strongyles was very high across the three coun- tries, i.e. $100.0 \%(97.5 \%$ one-sided $\mathrm{CI}=95.1-$ $100.0 \%)$ in Ireland, $91.5 \%(95 \% \mathrm{CI}=86.4-94.8 \%)$ in Switzerland and $95.5 \%(95 \% \mathrm{CI}=88.2-98.5 \%)$ in Italy.

Fig. 2 shows the distribution of H.contortus in sheep farms tested during the GLOWORM survey in the three pilot areas. The observed prevalence differed across the different European countries, showing high values in Switzerland $(96 / 124=77.4 \% ; 95 \% \mathrm{CI}=$ $69.0-84.4 \%)$ and Italy $(45 / 62=72.6 \% ; 95 \% \mathrm{CI}=$ $60.0-83.1 \%)$ with a very low prevalence in Ireland $(3 / 73=4.1 \% ; 95 \%$ CI $=0.9-11.5 \%)$. From the maps,

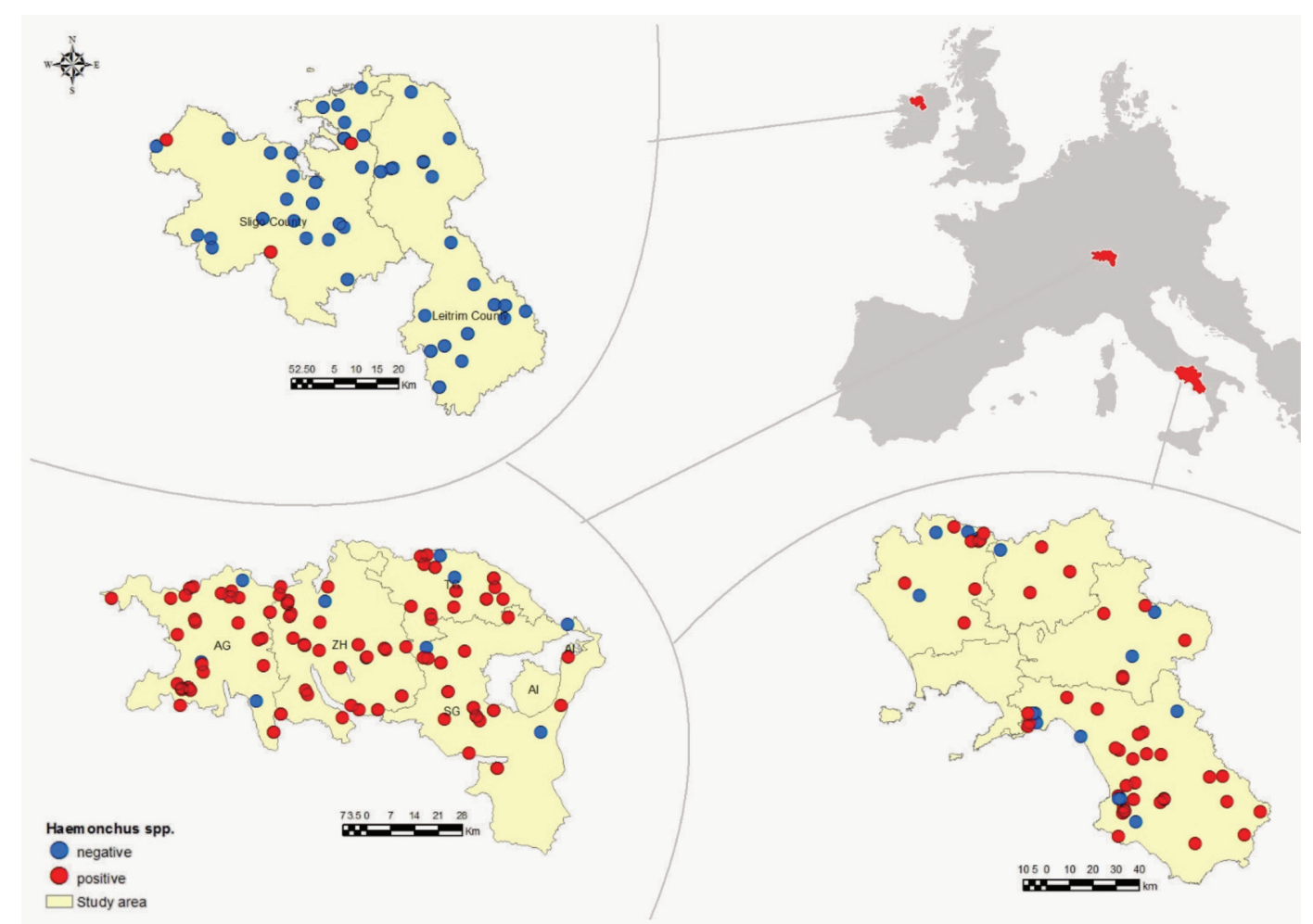

Fig. 2. Point distribution maps of H. contortus in sheep farms located in pilot areas of Ireland, Switzerland and Italy - GLOWORM project 2012-2013. 
Table 2. Prevalence and eggs per gram (EPG) of H. contortus (deduced from the percentage of larvae) in sheep farms from the studied pilot regions within the GLOWORM project in 2012-2013.

\begin{tabular}{|c|c|c|c|c|c|c|c|c|c|}
\hline \multirow{3}{*}{ Country } & \multirow{2}{*}{\multicolumn{3}{|c|}{$\begin{array}{l}\text { Number of } \\
\text { sampled } \\
\text { sheep farms }\end{array}$}} & \multicolumn{6}{|c|}{ Haemonchus contortus in sheep farms in pilot areas from three European countries } \\
\hline & & & & \multicolumn{3}{|c|}{$\begin{array}{l}\text { Number of positive farms }(\%) \\
\text { (95\% Confidence Interval) }\end{array}$} & \multicolumn{3}{|c|}{$\begin{array}{c}\text { Mean EPG } \\
\left(25^{\text {th }}-50^{\text {th }}-75^{\text {th }} \text { percentiles }\right)\end{array}$} \\
\hline & 2012 & 2013 & Total & 2012 & 2013 & Total & 2012 & 2013 & Total \\
\hline Ireland & 32 & 41 & 73 & $\begin{array}{c}1(3.1 \%) \\
(0.2-18.0 \%)\end{array}$ & $\begin{array}{c}2(4.9 \%) \\
(0.8-17.8 \%)\end{array}$ & $\begin{array}{c}3(4.1 \%) \\
(0.9-11.5 \%)\end{array}$ & $\begin{array}{c}10.1 \\
(.)\end{array}$ & $\begin{array}{c}4.0 \\
(1.4-3.9-.)\end{array}$ & $\begin{array}{c}6.0 \\
(1.4-6.5-.)\end{array}$ \\
\hline Switzerland & 52 & 72 & 124 & $\begin{array}{c}38(73.1 \%) \\
(58.7-84.0 \%)\end{array}$ & $\begin{array}{c}58(80.6 \%) \\
(69.2-88.6 \%)\end{array}$ & $\begin{array}{c}96(77.4 \%) \\
(69.0-84.4 \%)\end{array}$ & $\begin{array}{c}152.7 \\
(17.7-48.5-198.5)\end{array}$ & $\begin{array}{c}462.3 \\
(17.2-71.0-289.5)\end{array}$ & $\begin{array}{c}339.8 \\
(18.0-68.0-246.5)\end{array}$ \\
\hline Italy & 7 & 55 & 62 & $\begin{array}{c}4(57.1 \%) \\
(20.2-88.2 \%)\end{array}$ & $\begin{array}{c}41(74.5 \%) \\
(60.7-84.9 \%)\end{array}$ & $\begin{array}{c}45(72.6 \%) \\
(60.0-83.1 \%)\end{array}$ & $\begin{array}{c}413.2 \\
(3.7-13.0-1223.0)\end{array}$ & $\begin{array}{c}193.0 \\
(20.1-93.3-221.5)\end{array}$ & $\begin{array}{c}212.2 \\
(16.1-87.7-221.5)\end{array}$ \\
\hline
\end{tabular}

it is difficult to recognize the within-country spatial pattern in the distribution of the positive farms.

Table 2 reports, for each pilot area and year, the number of farms positive to $H$. contortus, the prevalence (number of positive farms over the total number of farms) and $95 \% \mathrm{CI}$, and the intensity of $\mathrm{H}$. contortus infection (mean EPG calculated on the positive pools, including the $25^{\text {th }}, 50^{\text {th }}$ and $75^{\text {th }}$ percentiles) deduced from the percentages of $H$. contortus larvae identified. The observed H. contortus prevalence did not differ between the two study years in any of the three pilot areas.

It should be noted that apart from H.contortus other GI strongyle genera (Teladorsagia, Trichostrongylus, Cooperia, Oesophagostomum/ Chabertia) were also detected in the coprocultures with different prevalence values across the three countries (data not shown).

The georeferenced results were modelled using a Bayesian geostatistical approach with correction for preferential sampling and accounting for environmental covariates (Catelan et al., 2015). Latent factor analysis highlighted the importance of seasonality and annual cyclicity within the countries (particularly in the Campania region of southern Italy), while mean temperature and rainfall dominated between country variations in the prevalence of $H$. contortus infection. The posterior predictive probabilities per grid cell for the pilot areas of the three investigated countries are reported in Fig. 3. The predicted prevalence of H. contortus was higher in Italy and Switzerland with a range of posterior predicted probabilities of $26.8 \%-90.8 \%$ and $33.7 \%-91.5 \%$, respectively. In Italy, it was possible to capture a weak spatial pattern with a northsouth gradient in the distribution of the parasite (Fig. 3c). The spatial pattern was less clear in Switzerland. H. contortus was very rare in sheep in Ireland and the spatial pattern almost flat. For only one grid cell the posterior predictive probability of infection was higher than $80 \%$ (Fig. 3a).

To show the prediction uncertainty and the withinarea variability, we report also the posterior probability for each grid cell to be in excess with respect to the observed mean prevalence $(4.1 \%$ in Ireland, $77.4 \%$ in Switzerland and $72.6 \%$ in Italy), which is shown in Fig. 4.
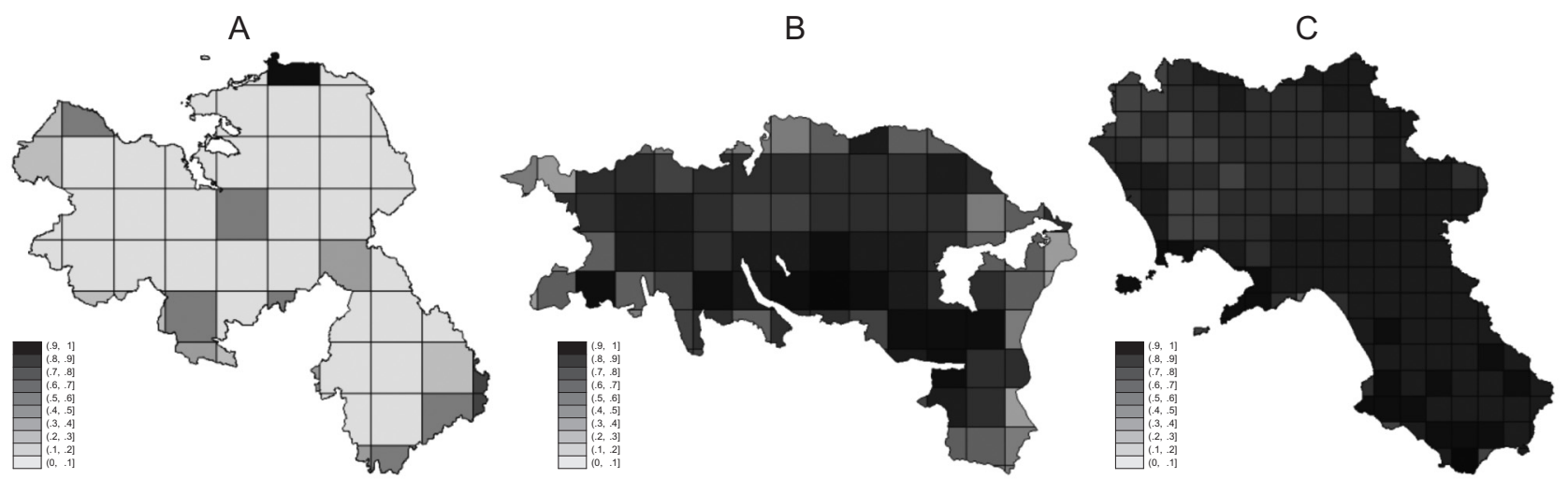

Fig. 3. Posterior predictive probability of H. contortus infection in pilot areas from Ireland (A), Switzerland (B) and Italy (C) - GLOWORM project 2012-2013. 

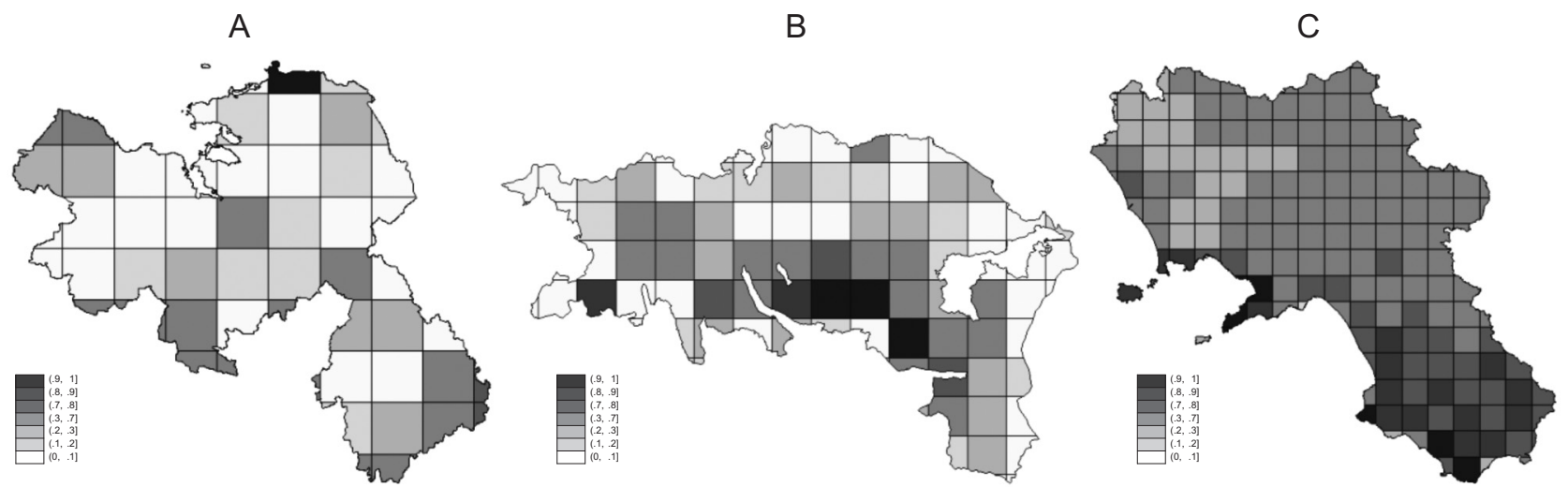

Fig. 4. Posterior probability in excess with respect to the average regional prevalence of H. contortus in pilot areas from Ireland (A), Switzerland (B) and Italy (C) - GLOWORM project 2012-2013.

The map of the Campania region of southern Italy confirms the spatial distribution of $H$. contortus reported in Fig. 3c, with the infection risk higher than the regional average on the coast and in the southern part of the region. We recognized a spatial pattern also in the pilot area of Switzerland with a south to north gradient (Fig. 3b). Despite the overall low predicted prevalence, it was possible to recognize one grid cell with higher than average risk of infection in Ireland. The spatial pattern was consistent with that of posterior predictive probabilities (Fig. 3a).

\section{Discussion}

Infections by GI strongyles are arguably the most important causes of suboptimal productivity in sheep (Nieuwhof and Bishop, 2005; Cringoli et al., 2008). During the GLOWORM project we collected updated and reliable data on these helminths through a standardized and harmonized approach based on cost-efficient, spatial sampling and diagnostic procedures involving pooled samples (Rinaldi et al., 2011) and the highly sensitive, accurate FLOTAC technique (Cringoli et al., 2010). As expected, a very high prevalence of GI strongyles was found in sheep farms in the pilot areas of the three investigated countries: $100.0 \%$ in Ireland, 91.5\% in Switzerland and $95.5 \%$ in Italy.

Grazing sheep are frequently parasitized by multiple species of GI strongyles (mixed infections), and knowledge of the species of GI strongyle present in areas where sheep farming is relevant for the local economy, is important in order to plan control and treatment strategies. Among the GI strongyles of sheep, we focused on H. contortus in the present paper, due to its pathogenicity, ubiquity, high biotic potential, dependence on climatic/environmental factors and propensity to develop resistance to anthelmintics. Based on the results gathered from GLOWORM, the overall prevalence of $H$. contortus in sheep farms in Europe was around 56\%. However, results differed across the countries investigated showing high prevalence rates in Switzerland (around 77\%) and Italy (around 73\%) and low rates in Ireland (around 4\%).

The large number of prevalence surveys and studies of field epidemiology in diverse regions provided a picture of scattered H. contortus distribution in Europe so far. In the present paper, we report results from a first harmonized, cross-sectional, coprological survey on the prevalence and distribution of $H$. contortus in sheep across an European north-south transect, conducted with the same methodology carried out in the same timeframe.

In agreement with the model proposed by Bolajoko et al. (2015), our field data confirm that H. contortus exhibits spatial heterogeneity in its infection pressure based on different, prevailing climate zones, i.e. in Ireland, Switzerland and Italy. In line with the distribution in the southern hemisphere (Kao et al., 2000), $H$. contortus tends to be more common and a greater risk to sheep health and production in warmer areas in the South, such as those of southern Italy (Musella et al., 2011, 2014) and Switzerland. It should be noted that the farms sampled in Switzerland were only located in the midland area (300-1,000 m altitude), where clinical haemonchosis is of considerable higher importance compared with the cooler mountainous regions (H. Hertzberg, personal communication).

Difference in $H$. contortus prevalence in the different countries studied could also depend on the management practice and treatment regimes used by the farmers. As an example, H. contortus is the predominant, resistant species against benzimidazole and moxidectin in Switzerland (Meyer, 2001; Scheuerle et al., 
2009). On the contrary, anthelmintic resistance is very rare in sheep in southern Italy, a region where anthelmintic use is limited (Cringoli et al., 2008; Rinaldi et al., 2014).

In the present study, in order to model the distribution of $H$. contortus in the various study areas, a Bayesian geostatistical model was developed with correction for preferential sampling and accounting for environmental covariates (Catelan et al., 2015). Spatial patterns of H. contortus distribution were detected in Switzerland and Italy with a north-south gradient in agreement with the findings reported by Musella et al. (2011) for the Campania region in southern Italy. The latent factor analysis highlighted the importance of seasonality and annual within-country cyclicity (particularly in the Campania region of southern Italy), while mean temperature and rainfall dominated in the variations of $H$. contortus infection from country to country. These results are in agreement with data from the literature; indeed the development and survival of free-living stages of $H$. contortus depend strongly on temperature and water availability; thus, transmission is strongly influenced by seasonal changes in the prevailing climate (Van Dijk et al., 2008; Morgan and Van Dijk, 2012). The susceptibility of $H$. contortus eggs and pre-infective stages ( $L 1$ and L2) to desiccation (Rossanigo and Gruner, 1995) is highly characteristic of this helminth species, limiting its distribution to areas with warm, moist summers and creating a natural barrier to development that results in sporadic development of the free-living stages (O'Connor et al., 2007). In previous studies conducted in southern Italy (Musella et al., 2011, 2014), sparse vegetation and rivers, mixed and permeable soil explained the spatial distribution of H. contortus in sheep.

The output generated by GLOWORM provide a spatial database incorporating parasitology, farm management, environmental information and climatic data. This common and standardised database is useful to develop cost-efficient sustainable sampling strategies, and multi-scale spatial models for parasite occurrence, including the impact of climate change and anthelmintic resistance in livestock in Europe (Bolajoko et al., 2015; Rose et al., 2015).

Predictive models (based either on time series analysis or on basic reproduction rate model) of $H$. contortus transmission to sheep have recently been developed by Bolajoko et al. (2015). However, collection of prevalence data derived from active surveillance, as those from the present cross-sectional survey, are necessary for continued models improvement, validation and meaningful predictions (Fox et al., 2012; Bolajoko et al., 2015). Promoting standardized cross-sectional surveys among practitioners and farmers is one of the priority areas for an integrated sustainable control of H. contortus and other helminths in sheep.

\section{Acknowledgements}

The authors would like to express their sincere appreciation to the farmers, the veterinarians and all the staff at CREMOPAR for their technical support in the laboratories. The excellent support from Regula Giezendanner (Swiss Extension and Health Service for Small Ruminants) and Erika Perler (Research Institute for Organic Farming, Frick, Switzerland) is greatly acknowledged. The research leading to these results has received funding from the European Union Seventh Framework Programme FP7KBBE-2011-5 under grant agreement no 288975.

\section{References}

Bolajoko MB, Rose H, Musella V, Bosco A, Rinaldi L, Van Dijk J, Cringoli G, Morgan ER, 2015. The basic reproduction quotient $\left(\mathrm{Q}_{0}\right)$ as a spatial predictor of the seasonality of ovine haemonchosis. Geospat Health 9, 333-350.

Burgess CG, Bartley Y, Redman E, Skuce PJ, Nath M, Whitelaw F, Tait A, Gilleard JS, Jackson F, 2012. A survey of the trichostrongylid nematode species present on UK sheep farms and associated anthelmintic control practices. Vet Parasitol 26, 299-307.

Burke JM, Kaplan RM, Miller JE, Terrill TH, Getz WR, Mobini S, Valencia E, Williams MJ, Williamson LH, Vatta AF, 2007. Accuracy of the FAMACHA system for on-farm use by sheep and goat producers in the southeastern United States. Vet Parasitol 147, 89-95.

Catelan D, Cecconi L, Grisotto L, Biggeri A, Rinaldi L, Cringoli G, 2015. Sampling designs in veterinary parasitological surveillance. Geospat Health, in press.

Charlier J, van der Voort M, Kenyon F, Skuce P, Vercruysse J, 2014. Chasing helminths and their economic impact on farmed ruminants. Trends Parasitol 30, 361-367.

Cringoli G, Rinaldi L, Maurelli MP, Utzinger J, 2010. FLOTAC: new multivalent techniques for qualitative and quantitative copromicroscopic diagnosis of parasites in animals and humans. Nat Protoc 5, 503-515.

Cringoli G, Veneziano V, Jackson F, Vercruysse J, Greer AW, Fedele V, Mezzino L, Rinaldi L, 2008. Effects of strategic anthelmintic treatments on the milk production of dairy sheep naturally infected by gastrointestinal strongyles. Vet Parasitol 156, 340-345.

Domke AV, Chartier C, Gjerde B, Leine N, Vatn S, Stuen S, 2013. Prevalence of gastrointestinal helminths, lungworms and liver fluke in sheep and goats in Norway. Vet Parasitol 1, 
40-48.

Fox NJ, Marion G, Davidson RS, White PCL, Hutchings MR, 2012. Livestock helminths in a changing climate: approaches and restrictions to meaningful predictions. Animal 2, 93-107.

Höglund J, Gustafsson K, Ljungström BL, Engström A, Donnan A, Skuce P, 2009. Anthelmintic resistance in Swedish sheep flocks based on a comparison of the results from the faecal egg count reduction test and resistant allele frequencies of the betatubulin gene. Vet Parasitol 6, 60-68.

Kao RR, Leathwick DM, Roberts MG, Sutherland IA, 2000. Nematode parasites of sheep: a survey of epidemiological parameters and their application in simple model. Parasitology 121, 85-103.

Kaplan RM, Burke JM, Terrill TH, Miller JE, Getz WR, Mobini S, Valencia E, Williams MJ, Williamson LH, Larsen M et al., 2004. Validation of the FAMACHA eye color chart for detecting clinical anemia in sheep and goats on farms in the southern United States. Vet Parasitol 123, 105-120.

Kenyon F, Sargison ND, Skuce PJ, Jackson F, 2009. Sheep helminth parasitic disease in south eastern Scotland arising as a possible consequence of climate change. Vet Parasitol 163, 293-297.

MAFF, 1986. Manual of Veterinary Parasitological Laboratory Techniques. Her Majesty's Stationary Office, London, 20-27 pp.

Meyer, A, 2001. Verbreitung von benzimdazol-resistenzen bei den trichostrongyliden von schafen und ziegen in der Schweiz. $\mathrm{PhD}$ thesis, University of Zurich (in German).

Morgan ER, Charlier J, Hendrickx G, Biggeri A, Catelan D, von Samson-Himmelstjerna G, Demeler J, Müller E, van Dijk J, Kenyon F et al., 2013. Global change and helminth infections in grazing ruminants in Europe: impacts, trends and sustainable solutions. Agriculture 3, 484-502.

Morgan ER, Van Dijk J, 2012. Climate and the epidemiology of gastrointestinal nematode infections of sheep in Europe. Vet Parasitol 189, 8-14.

Musella V, Catelan D, Rinaldi L, Lagazio C, Cringoli G, Biggeri A, 2011. Covariate selection in multivariate spatial analysis of ovine parasitic infection. Prev Vet Med 99, 69-77.

Musella V, Rinaldi L, Lagazio C, Cringoli G, Biggeri A, Catelan D, 2014. On the use of posterior predictive probabilities and prediction uncertainty to tailor informative sampling for parasitological surveillance in livestock. Vet Parasitol 205, 158168.

Nieuwhof GJ, Bishop SC, 2005. Costs of the major endemic dis- eases in Great Britain and the potential benefits of reduction in disease impact. Anim Sci 81, 23-29.

O’Connor LJ, Kahn LP, Walkden-Brown SW, 2007. Moisture requirements for the free-living development of Haemonchus contortus: quantitative and temporal effects under conditions of low evaporation. Vet Parasitol 150, 128-138.

O’Connor LJ, Walkden-Brown SW, Kahn LP, 2006. Ecology of the free-living stages of major trichostrongylid parasites of sheep. Vet Parasitol 142, 1-15.

Rinaldi L, Biggeri A, MusellaV, de WaalT, Hertzberg H, Mavrot F, Torgerson P, Selemetas N, CollT, Bosco A et al., 2015. Sheep and Fasciola bepatica in Europe: the experience from GLOWORM. Geospat Health 9, 309-317.

Rinaldi L, Coles GC, Maurelli MP, Musella V, Cringoli G, 2011. Calibration and diagnostic accuracy of simple flotation, McMaster and FLOTAC for parasite egg counts in sheep. Vet Parasitol 177, 345-352.

Rinaldi L, Cringoli G, 2014. Exploring the interface between diagnostics and maps of neglected parasitic diseases. Parasitology 28, 1-8.

Rinaldi L, Levecke B, Bosco A, Ianniello D, Pepe P, Charlier J, Cringoli G, Vercruysse J, 2014. Comparison of individual and pooled faecal samples in sheep for the assessment of gastrointestinal strongyle infection intensity and anthelmintic drug efficacy using McMaster and Mini-FLOTAC. Vet Parasitol 205, 216-223.

Rose H, Rinaldi L, Bosco A, Mavrot F, de Waal T, Skuce P, Charlier J, Torgerson PR, Hertzberg H, 2015. Widespread anthelmintic resistance in European farmed ruminants: a systematic review. Vet Rec, in press.

Rossanigo CE, Gruner L, 1995. Moisture and temperature requirements in faeces for the development of free-living stages of gastrointestinal nematodes of sheep, cattle and deer. J Helminthol 69, 357-362.

Scheuerle MC, Mahling M, Pfister K, 2009. Anthelminthic resistance of Haemonchus contortus in small ruminants in Switzerland and Southern Germany. Wien Klin Wochenschr 121, 46-49.

Van Dijk J, David GP, Baird G, Morgan ER, 2008. Back to the future: developing hypotheses on the effects of climate change on ovine parasitic gastroenteritis from historical data. Vet Parasitol 158, 73-84.

van Wyk JA, Mayhew E, 2013. Morphological identification of parasitic nematode infective larvae of small ruminants and cattle: a practical lab guide. Onderstepoort J Vet Res 80, 539. 